\title{
Ambulatory gastrojejunal manometry in severe motility-like dyspepsia: lack of correlation between dysmotility, symptoms, and gastric emptying
}

\author{
A Wilmer, E Van Cutsem, A Andrioli, J Tack, G Coremans, J Janssens
}

\begin{abstract}
Background-Previous studies have failed to identify manometric patterns of gastrointestinal motor activity that can distinguish dyspepsia from health.

Aims-To test the hypothesis that the combined use of prolonged, ambulatory, antrojejunal manometry and computer aided analysis in patients selected for the severity of their symptoms could reveal new insights into gastrointestinal motor activity in patients with severe motilitylike dyspesia

Methods-Twenty four hour antrojejunal ambulatory manometry was performed in 14 patients and 10 healthy volunteers. Parameters characterising digestive and fasted motility were obtained by a validated computer program and visual analysis. Scoring systems quantified the degree of dysmotility as well as the severity of symptoms. Gastric emptying times were measured in each patient.
\end{abstract}

Results-There was a high prevalence of antral and jejunal dysmotility both during the interdigestive period ( $71 \%$ of patients) and in the postprandial period $(78 \%)$. During the interdigestive period there was a reduced incidence of antral and jejunal phases, a larger contribution of phase 2 during migrating motor complex cycles, and aberrant configuration of jejunal phase 3 in $29 \%$ of patients. Postprandially, the most frequent finding was antral $(29 \%$ of patients) or jejunal (29\%) hypomotility or hypermotility. Minute rhythm was present both during the postprandial (29\% of patients) and the interdigestive period $(21 \%)$. There was no positive correlation between symptom scores, gastric half emptying times, or motility scores.

Conclusion-Even with the use of prolonged recordings and advanced computer aided analysis, it is not possible to identify a specific motor pattern which can discriminate patients with severe motility-like dyspepsia from those with other diseases or even healthy individuals. Clinical symptoms or gastric half emptying times are poor predictors of gastrointestinal dysmotility in patients with functional dyspepsia.

(Gut 1998;42:235-242)

Keywords: dyspepsia; ambulatory; gastrointestinal manometry; gastric emptying
Abnormalities in gastrointestinal motor function constitute a possible aetiopathogenic mechanism of symptom production in patients with functional dyspepsia. This hypothesis has been pursued in several studies which used stationary short term perfusion techniques to assess antral and upper intestinal motor activity. ${ }^{1-3}$ Antral hypomotility can be expected in $25-40 \%$ of patients and appears to be the most frequent yet non-specific feature of dysmotility. ${ }^{14}$ Motor patterns suggestive of small intestinal dysmotility with or without associated gastric dysmotility have also been described in patients with dyspepsia, both with conventional stationary ${ }^{135}$ as well as with ambulatory antroduodenal ${ }^{6}$ and duodenojejunal manometry. ${ }^{7}$ The reported motor abnormalities included absence or reduced incidence of migrating motor complex (MMC) cycles, ${ }^{357}$ aberrant propagation of phase 3 of the MMC, ${ }^{57}$ longer durations of phase $2,{ }^{7}$ a higher prevalence of burst activity,,$^{1-367}$ and an abnormal motor response after a meal. ${ }^{7}$ Ambulatory manometric evaluation has been noted to be superior to stationary manometry for evaluating patients with functional dyspepsia ${ }^{6}$ because it offers the possibility of studying motor function-especially interdigestive motor function - for prolonged periods of time and also because it increases the chances of detecting a possible relation between symptoms and motor abnormalities. ${ }^{8-10}$ As the technique involves digitisation of the pressure signals it also makes the tracings accessible to more detailed computer analysis. As has been done by others previously, we have recently developed and validated a computer program that permits significantly faster and more accurate offline analysis of ambulatory manometric tracings in the human gut. ${ }^{11-14}$ Despite numerous studies, no pattern of gastrointestinal dysmotility specific to functional dyspepsia has emerged. In this study we aimed to combine three factors that theoretically could increase the possibilities of detecting more specific motor abnormalities in patients with motilitylike dyspesia: we deliberately selected patients with severe symptoms; we combined visual with computerised analysis of the tracings to obtain more detailed and accurate data; and we studied both antral and jejunal motor activity simultaneously on an ambulatory basis over a prolonged period of time.

\section{Methods}

SUBJECTS

Fourteen patients (11 females and three males; mean age 30 years, range 17-54) with
Accepted for publication 23 September 1997 
the diagnosis of severe motility-like dyspepsia were included in the study. ${ }^{15}$ The control group consisted of 10 healthy, age matched volunteers taking no medication (four females and six males). Patients were selected on the basis of the severity of their symptoms. The inclusion criterion was a history of at least two symptoms from a five symptom complex (upper abdominal pain, vomiting, nausea, early satiety, postprandial bloating or fullness) of at least six months duration and at least moderate severity as defined by a numerical symptom score $(0=$ absent, 1 = mild (awareness of symptom), $2=$ moderate (interference with daily activities), 3 $=$ severe (incapacitating)). None of the patients complained of alterations in bowel habit, flatulence, or lower abdominal pain, and none had undergone previous abdominal surgery other than appendectomy. In all patients organic disease was excluded by clinical and biochemical examination, ultrasound of the upper abdomen, oesophagogastroduodenoscopy, and barium $x$ ray radiography of the small bowel. In 11 patients antral biopsy specimens were taken to test for Helicobacter pylori. Four of the 11 patients tested positive. Gastric emptying for solids was studied in all patients with the ${ }^{13} \mathrm{C}$ octanoic acid breath test ${ }^{16}$ and 10 of 14 patients (71\%) appeared to have delayed gastric emptying (mean $\mathrm{t}_{1 / 2} 130$ minutes, range 70-276; 90th percentile 101 minutes; mean $t_{1 / 2}$ in healthy volunteers 72 minutes). All medications known to affect gastrointestinal motility were stopped three days before the manometric study.

\section{RECORDING TECHNIQUE}

Recordings of antral and jejunal intraluminal pressures were performed using a $250 \mathrm{~cm}$ long silicon catheter (maximal outer diameter 4 $\mathrm{mm}$ ) with six strain gauge pressure transducers (Königsberg, California, USA). The probe was introduced via the nose and positioned under fluoroscopic control in such a way that the most distal of the three proximal sensors, which were $4 \mathrm{~cm}$ apart, was located in the antrum at the level of the pylorus or just distal to it. The other three sensors, which were also $4 \mathrm{~cm}$ apart, were located in the proximal jejunum with the first sensor being $30 \mathrm{~cm}$ distal to the last sensor of the first group of three sensors. After correct positioning the probe was connected to a portable digital recording device (Digitrapper, Synectics, Sweden). The digitrapper had an internal memory of $4 \mathrm{MB}$ and a sampling frequency of $4 \mathrm{~Hz}$ for each of the six recording channels.

\section{STUDY DESIGN}

Following an overnight fast of at least 12 hours, the recording probe was introduced as described above and fixed to the subject's nose with adhesive tape. The subjects were asked to eat two meals of equal energy load $(3.34 \mathrm{MJ})$ and chemical composition ( $40 \%$ fat, $45 \%$ carbohydrates, $15 \%$ protein). One meal was administered at around $12 \mathrm{am}$, the second meal at around $6 \mathrm{pm}$. Subjects were not allowed to eat or drink anything but water during the study. They were also asked to refrain from smoking. During the study the volunteers and patients were free to follow their daily routines but had to sleep in the hospital. A diary was provided to record the times of meals, the time when the subjects laid down in bed, and possible episodes of pain or nausea or other type of discomfort. Before and at the end of the study and after every meal the position of the probe was checked by fluoroscopy.

\section{ANALYSIS}

At the end of the study the data stored in the digitrapper were transferred to a personal computer for display and computer aided analysis. By visual inspection the pressure sensor most representative of antral motor activity could be identified and labelled on the computer screen. The analysis consisted of the following five steps.

\section{Recognition of individual contractions}

On the basis of previous experiments which validated the recognition of individual contractions in the human gut by the computer program, ${ }^{14}$ an individual contraction was defined as pressure activity lasting for at least 1.25 seconds at $6 \mathrm{~mm} \mathrm{Hg}$ and 0.6 seconds at $9 \mathrm{~mm}$ $\mathrm{Hg}$ above baseline pressure. Propagation of individual phasic pressure waves was calculated at the level of the jejunum: a contraction was considered to be propagated if it was recorded at all three channels of the second group of three sensors, thus propagating over at least 8 $\mathrm{cm}$, within a time window that allowed a minimal velocity of $0.7 \mathrm{~cm}$ per second and a maximal velocity of $4 \mathrm{~cm}$ per second. ${ }^{17} 18$

Identification of the fed period and of the phases of the $M M C$ cycle

The fed period comprised the time from the start of the meal until the arrival of the first phase 3 of the MMC, ${ }^{10}{ }^{19}$ irrespective of its site of origin (antrum or jejunum) or until a period of quiescence (less than three contractions per 10 minutes at the jejunal level for a period of at least 10 minutes). ${ }^{9}$ The interdigestive period was divided into the classic phase 3 , phase 2 , and phase 1 motor activity with the aid of the computer algorithm according to well established criteria. ${ }^{14}{ }^{19}{ }^{20}$ Even though the accuracy of the computer program in recognising small intestinal phase $3 \mathrm{~s}$ is $96 \%,{ }^{14}$ visual analysis was used to confirm correct identification of phase 3 , phase 1 , and phase 2 . Antral phase 3 s were always marked visually. Phase 3 motor activity was also analysed visually for normal initiation and propagation. A phase 3 was considered to be abnormally initiated if it began simultaneously in all three jejunal channels and to be abnormally propagated if propagation at an individual channel was temporarily interrupted (more than 30 seconds) or if there was retropropagation.

Identification of special motor patterns in the postprandial period and during phase 2

Propagating clustered contractions (PCCs) in the jejunum were detected by visual analysis. PCCs were defined as repetitive (two to seven contractions), phasic pressure activity at slow 
wave rhythm (10-12 contractions per minute), propagated over at least $8 \mathrm{~cm}$, preceded and followed by a period of quiescence of at least 30 seconds. ${ }^{21-23}$ If PCCs were present at intervals of one to two minutes during at least 20 minutes these episodes were labelled as minute rhythm. Bursts of phasic pressure activity at individual channels were defined as sustained, non-propagating, phasic pressure activity with a contractile incidence of at least nine per minute for more than two minutes, not followed by motor quiescence. ${ }^{3}$

Table 1 Parameters characterising the MMC cycle, jejunal phase 3, and phase 2 motor activity during the nocturnal period in dyspeptics and controls

\begin{tabular}{|c|c|c|c|}
\hline Parameter & Dyspeptics & Controls & $p$ Value \\
\hline \multicolumn{4}{|l|}{ MMC cycle } \\
\hline Cycle length (min) & $111 \quad(16)$ & 68 & $<0.03$ \\
\hline Per cent phase 2 of $M M C$ & $70.1 \quad(5.4)$ & $46.8 \quad(4.3)$ & $<0.004$ \\
\hline Per cent phase 1 of $M M C$ & $24.1 \quad(5.2)$ & 45.1 (3.9) & $<0.005$ \\
\hline \multicolumn{4}{|l|}{ Phase 3} \\
\hline No of phase $3 / \mathrm{h}$ & $0.53(0.08)$ & $0.94(0.06)$ & $<0.003$ \\
\hline Duration (min) & $5.4(0.3)$ & $5.1(0.2)$ & NS \\
\hline $\operatorname{VEL}(\mathrm{cm} / \mathrm{min})$ & $5.2(0.5)$ & $5.1 \quad(0.7)$ & NS \\
\hline MI & $5.84(0.1)$ & $5.77(0.1)$ & NS \\
\hline CPM (contractions/min) & $10.2(0.1)$ & $10.1(0.2)$ & NS \\
\hline $\operatorname{AMPL}(\mathrm{mm} \mathrm{Hg})$ & $26 \quad(2)$ & $26 \quad(0.8)$ & NS \\
\hline DUR-C (sec) & $3.2(0.2)$ & $3.4(0.1)$ & NS \\
\hline \multicolumn{4}{|l|}{ Phase 2} \\
\hline MI & $3.65(0.3)$ & $3.54(0.1)$ & NS \\
\hline CPM (contractions/min) & $1.3(0.3)$ & $1.3(0.1)$ & NS \\
\hline $\mathrm{AMPL}(\mathrm{mm} \mathrm{Hg})$ & $23 \quad(2)$ & $22 \quad(1)$ & NS \\
\hline DUR-C (sec) & $3.2(0.2)$ & $3.4(0.1)$ & NS \\
\hline$\%$ PPC & $9.1 \quad(1.3)$ & $7.8 \quad(1.3)$ & NS \\
\hline $\mathrm{PCCs} / \mathrm{h}^{\star}$ & $0.0 \quad(0-0.4)$ & $0.1 \quad(0-0.3)$ & NS \\
\hline
\end{tabular}

Results expressed as mean (SEM) or ${ }^{\star}$ median (interquartile range).
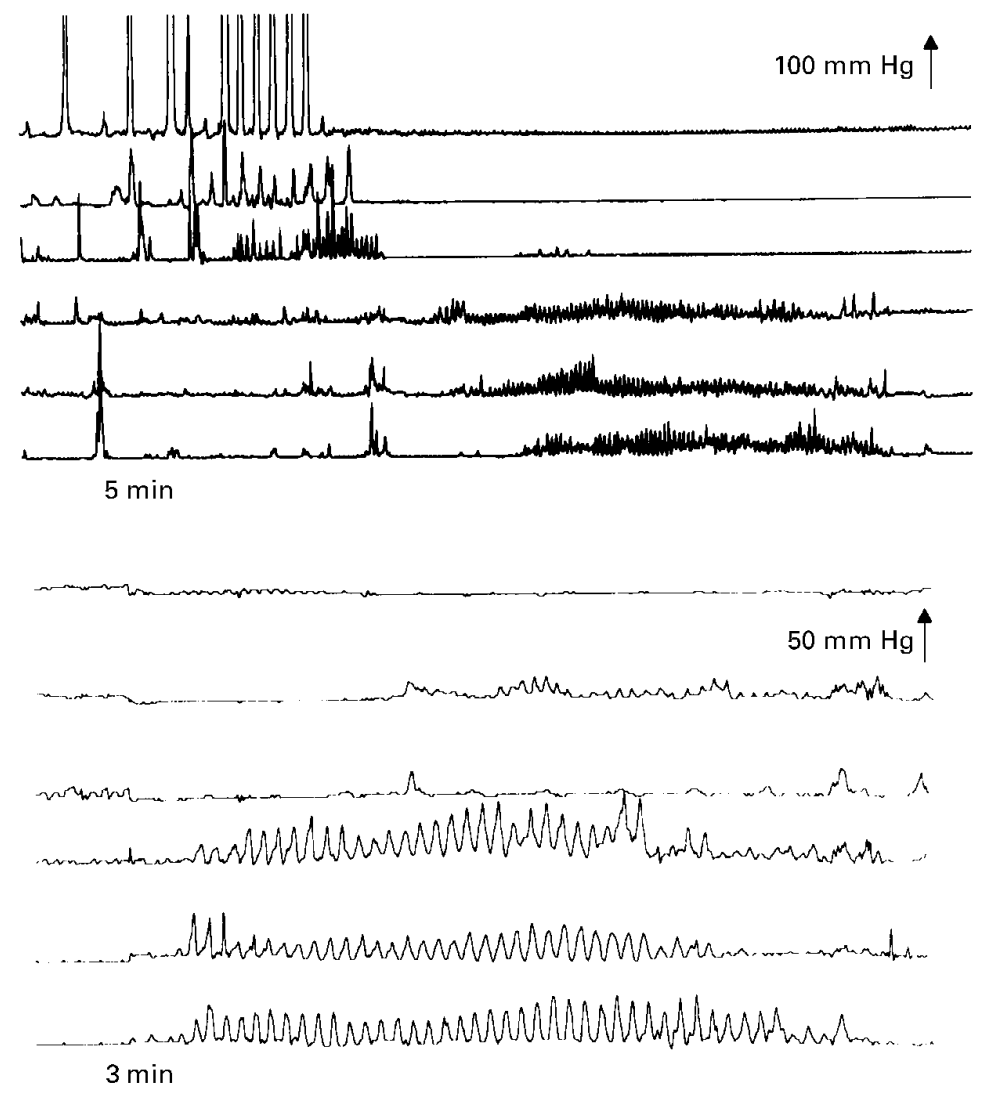

Figure 1 Fasted manometric recordings of the antrum (upper three channels) and of the jejunum (lower three channels) in two patients with motility-like dyspepsia. The upper trace shows normal initiation and migration of a phase 3 with an antral component; the lower trace shows a jejunal phase 3 with simultaneous initiation.
Calculation of individual parameters

The data presented for interdigestive motility are data derived from motor activity at night with only complete jejunal MMC cycles taken into account. The nocturnal period was defined as the moment when the individual went to bed in the evening until he or she got up the next morning. For the fed periods, phase 3 and phase 2 motor activity, the computer calculated the cumulative motility index $(\mathrm{MI}=\ln$ $($ area/min +1$)$ ), the number of contractions per min (CPM), the duration of individual contractions in seconds (DUR-C), and the amplitude in $\mathrm{mm} \mathrm{Hg}$ (AMPL). In addition, for the fed period and for phase 2 , the percentage of propagated contractions (\%PPC) was computed. The number of phase $3 \mathrm{~s}$, the cycle length, the relative contribution of phase 2 and phase 1 during the MMC cycle, the duration of the fed pattern, velocity (VEL) of migration, and duration of phase 3 were also determined by the computer. Antral MIs over time (calculation of the $\mathrm{MI}$ in 30 minute periods over the first three hours after the meal) were calculated after the first meal. In 5/14 patients and in 4/10 controls the catheter migrated several centimetres during the night; the occurrence of antral phase 3 motor activity, which can only be identified accurately with at least two sensors in the antrum, could therefore not be assessed reliably in all patients. At the level of the stomach therefore, detailed quantitative analysis was performed only for the postprandial period; for the interdigestive period only the number of antral phase $3 \mathrm{~s}$ were recorded in those individuals where there was no catheter migration. At the level of the jejunum interdigestive motor activity throughout the MMC cycle and all periods of postprandial motility could be evaluated.

\section{Evaluation of symptom episodes and calculation} of dysmotility scores

Symptom episodes were analysed visually for signs of abnormal motor activity over a time window of 10 minutes before and 10 minutes after the patient reported a symptom. To study a possible correlation between symptom scores, the presence or absence of weight loss, gastric half emptying times, and motor activity, a scoring system of dysmotility was devised both for interdigestive motor activity (IMA score) and for the postprandial motor activity (PMA score).

Normality or abnormality of interdigestive motor activity was scored with four parameters: number of jejunal phase $3 \mathrm{~s}$ ( 0 points if within 2 SD of the mean of the healthy volunteers, 1 point if outside of mean (2 SD)); configuration of phase 3 ( 0 points if normal, 1 point if abnormal initiation or aberrant propagation of at least one phase 3); presence of minute rhythm or presence of at least two bursts ( 0 points if absent, 1 point if present); and relative contribution of phase 2 to the MMC cycle (0 points if within $2 \mathrm{SD}$ of the mean of healthy volunteers, 1 point if outside of mean (2 SD)).

For the PMA score the following four parameters were included: duration of the 
Table 2 Parameters characterising antral and jejunal postprandial motor activity in dyspeptics and normal controls

\begin{tabular}{|c|c|c|c|}
\hline Parameter & Dyspeptics & Controls & $p$ Value \\
\hline \multicolumn{4}{|l|}{ Antrum } \\
\hline MI & $3.56(0.25)$ & $3.91(0.24)$ & NS \\
\hline $\mathrm{CPM}(\text { contractions } / \mathrm{min})^{\star}$ & $0.4 \quad(0.3-0.7)$ & $0.9(0.5-1.0)$ & NS \\
\hline AMPL $(\mathrm{mm} \mathrm{Hg})$ & $49 \quad(5)$ & $50 \quad(4)$ & NS \\
\hline DUR-C (sec) & $4.7 \quad(0.2)$ & $4.9 \quad(0.2)$ & NS \\
\hline \multicolumn{4}{|l|}{ Jejunum } \\
\hline Duration (min) & $270 \quad(15)$ & $266 \quad(15)$ & NS \\
\hline MI & $4.42(0.1)$ & $4.39(0.1)$ & NS \\
\hline CPM (contractions/min) & $3.1(0.3)$ & $3.0 \quad(0.1)$ & NS \\
\hline $\operatorname{AMPL}(\mathrm{mm} \mathrm{Hg})$ & $21 \quad(1)$ & $22 \quad(1)$ & NS \\
\hline DUR-C (sec) & $3.5(0.1)$ & $3.4(0.1)$ & NS \\
\hline$\%$ PPC & $17.4 \quad(2.1)$ & $13.1(1.6)$ & NS \\
\hline $\mathrm{PCCs} / \mathrm{h}^{\star}$ & $0.6(0.4-2.8)$ & $0.5 \quad(0.2-2.0)$ & NS \\
\hline
\end{tabular}

Results expressed as mean (SEM) or ${ }^{\star}$ median (interquartile range).

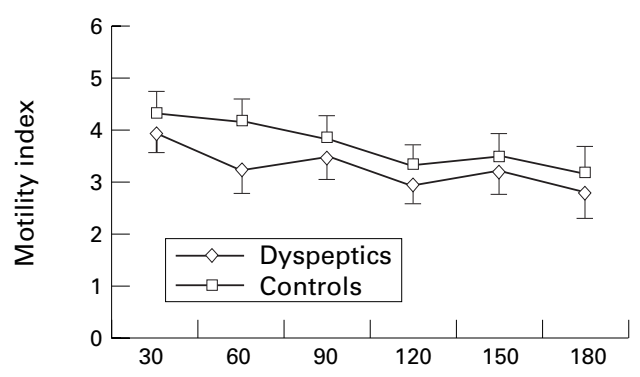

Time (minutes) since start of the mea

Figure 2 Antral motility indices (means (2 SD)) determined over 30 minute periods during the first three hours after a $3.34 \mathrm{MF}$ meal.

postprandial motor pattern ( 0 points if within 2 $\mathrm{SD}$ of the mean of the healthy volunteers, 1 point if less than the mean minus $2 \mathrm{SD})$; antral or jejunal motility indices in 30 minute periods for the first three hours after the meal $(0$ points if within $2 \mathrm{SD}$ of the mean of the healthy volunteers, 1 point if outside of mean (2 SD)); and presence of minute rhythm or presence of at least two bursts ( 0 points if absent, 1 point if present). The maximum score for the IMA and PMA was four points each.

\section{STATISTICS}

At the level of the jejunum data were calculated as means of the values recorded by all three pressure sensors. At the level of the stomach, parameters were calculated from the sensor that had been previously identified as being most representative of antral motor activity. All data were tested for symmetry of distribution. For the vast majority of variables the distribution was found to have only moderate skewness. Therefore, as an appropiate measure of central tendency the overall mean (SEM) for either the dyspeptic or the healthy volunteers group was used. The distribution of the number of PPCs per hour during phase 2 and the fed state, of the contractions per minute in the antrum during the postprandial state, and of the number of antral phase $3 \mathrm{~s}$ was found to be heavily skewed: in these cases we used the median and interquartile range (IQR) for descriptive statistics and the Mann-Whitney test for group comparisons. All other variables for dyspeptics or normals were compared by the unpaired $t$ test. The motility indices over time during the postprandial period were compared by analysis of variance with Scheffe's F test for post hoc comparisons. Relations between symptom scores, gastric emptying times, and dysmotility scores were examined by correlation analysis. Differences were considered to be significant if the $\mathrm{p}$ value was less than 0.05 .

\section{Results}

PATIENTS AND MANOMETRIC TECHNIQUE

Nine of the fourteen patients (64\%) had symptom scores of 6 or higher out of 15 possible points, six patients $(43 \%)$ were losing weight, and 10 patients $(71 \%)$ had severely delayed gastric emptying (table 4 ). The mean recording time was $21.2(0.5)$ hours in patients and 22.6 (0.4) hours in controls. One subject complained of slight nasal and pharyngeal discomfort due to the procedure. The time for proper positioning of the probe varied from 20 minutes to 1.5 hours. Catheter migration occurred in 5/14 (36\%) patients and in 4/10 ( $40 \%$ ) healthy volunteers, usually between five and eight hours after the second meal. Reliable, continuous assessment of antral motor activity throughout the night was thus not possible in these individuals.

\section{INTERDIGESTIVE MOTILITY: MMC CYCLE AND}

PHASE 3

The nocturnal period lasted $8.0(0.4)$ hours in the healthy volunteers and $8.5(0.3)$ hours in the dyspeptics. Every indiviudal in both groups had at least one complete MMC cycle during this period. In dyspeptics the mean cycle length was 111 (16) minutes, whereas in controls it was $68(7)$ minutes $(p<0.03)$. This difference was due to an increase in the contribution of phase 2 to the MMC cycle $(70.1$ (5.4)\% in the dyspeptics versus 46.8 (4.3)\% in the healthy volunteers, $p<0.004)$. The number of jejunal phase $3 \mathrm{~s}$ over the whole recording time was significantly lower in dyspeptics than in controls (6.4 (0.9) versus $12.6(1.5), \mathrm{p}<0.001)$. This difference remained significant even when adjusting the number of phase $3 \mathrm{~s}$ for the duration of the nocturnal period $(0.53$ (0.08) per hour in dyspeptics versus 0.94 (0.06) per hour in controls, $\mathrm{p}<0.001)$. Table 1 summarises the parameters characterising jejunal phase 3 . No significant differences were noted for the velocity of migration of phase 3 or for the contractile incidence, amplitude, or duration of individual contractions. In $4 / 14$ patients (29\%) there was a disturbance of either the initiation or the propagation of jejunal phase 3 motor activity (fig 1). In the nine dyspeptics and six healthy volunteers in whom it was possible to monitor antral motor activity throughout the whole study period, at least one antral phase 3 was observed in each individual. In the patient group a median of 2 (IQR 1 to 2) antral phase $3 \mathrm{~s}$ were recorded, while in the control group a median of 3.5 (IQR 3 to 4 ) antral phase $3 \mathrm{~s}$ were noted $(\mathrm{p}=0.04)$.

INTERDIGESTIVE MOTILITY: PHASE 2

There were no significant differences between dyspeptics and controls for the motility indices, contractile incidence, amplitude, duration, or percentage of propagated, individual 

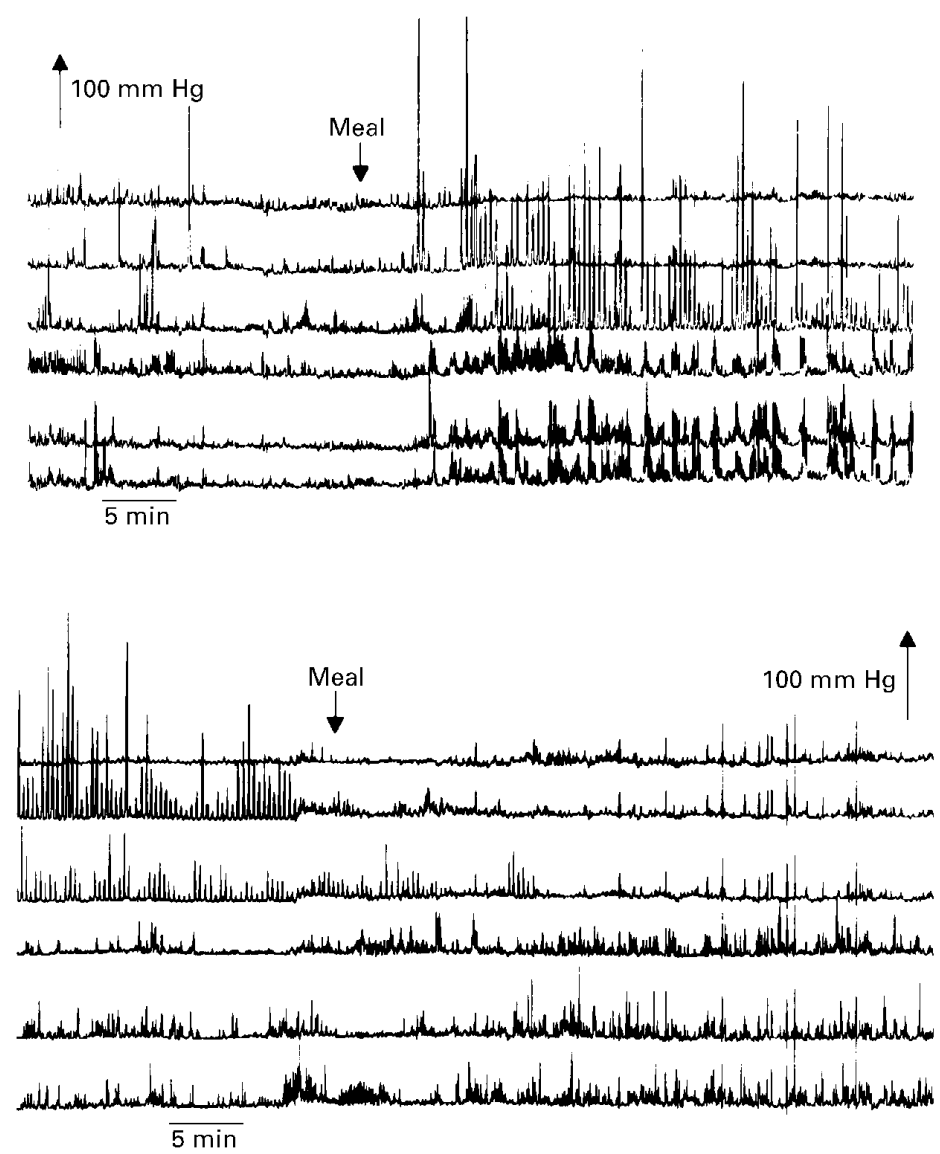

Figure 3 Postprandial manometric recordings of the antrum (upper three channels) and of the jejunum (lower three channels) in two patients with motility-like dyspepsia. The upper panel shows a normal conversion to a postprandial motor pattern; in the lower panel the characteristic increase in antral motor activity after the meal is absent.

contractions (table 1). Even though some patients had a high incidence of PCCs per hour (range in dyspeptics $0-6$, in controls $0-0.8$ ), group comparisons did not reveal any significant difference between dyspeptics and controls. In $3 / 14$ patients $(21 \%)$, episodes of minute rhythm were observed. Three patients $(21 \%)$, not the same as those with minute rhythm, had two or more episodes of jejunal, segmental bursts lasting longer than two minutes. Patterns of minute rhythm or burst episodes were not observed in the healthy individuals.
POSTPRANDIAL MOTILITY

When comparing the duration of the fed pattern, cumulative motility indices, contractile incidence, amplitude and duration of individual contractions, or the number of PCCs per hour during the postprandial period, no significant differences were found between dyspeptic patients and controls either in the antrum or in the jejunum (table 2). As with phase 2, the number of PCCs per hour varied greatly and within both groups of subjects (range in dyspeptics $0-6$, in controls $0-3$ ). A comparison of mean antral motility indices for the first three hours of the postprandial period revealed no significant differences between the two groups (fig 2). However, three patients $(21 \%)$ had periods of postcibal antral hypomotility (values lower than the mean (2 SD) of healthy volunteer values, fig 3 ), and one patient had antral hypermotiltiy between 30 and 120 minutes after ingestion of the meal. Two patients had postprandial jejunal hypomotility, and two patients had postcibal jejunal hypermotility (MI lower or higher than the mean (2 SD) of healthy volunteer values). Four patients had a normal motility index, but in all four, episodes of a minute rhythm pattern not characteristic of normal postprandial jejunal motility were observed (fig 4). Two patients had several episodes of jejunal segmental bursts. In three patients the time period until reappearance of phase 3 was less than the mean (2 SD) in healthy volunteers.

SYMPTOM EPISODES AND MOTOR ACTIVITY

Eight patients $(57 \%)$ reported a total of 19 episodes of abdominal discomfort or pain, bloating, or epigastric fullness or nausea (mean 2.4 (0.4) episodes per patient, range $0-5)$. The most frequently reported symptoms were postprandial epigastric pain and fullness. Inspection of the time window before and after the patient recorded the onset of symptoms showed a temporal association with abnormal motor patterns for only four symptom episodes $(21 \%)$. The abnormal motor patterns observed included an episode of minute rhythm at the start of the meal in one patient, and two episodes of high amplitude, long duration, non-propagating, segmental, jejunal contractions with a frequency of two per minute lasting three minutes during the postprandial period

Table 3 Dysmotility scores for patients for both interdigestive motor activity (IMA score) and postprandial motor activity (PMA score)

\begin{tabular}{|c|c|c|c|c|c|c|c|c|c|c|}
\hline \multirow[b]{2}{*}{ Patient } & \multicolumn{5}{|c|}{ Interdigestive motor activity score } & \multicolumn{5}{|c|}{ Postprandial motor activity score } \\
\hline & $\begin{array}{l}\text { No of } \\
\text { phase 3s }\end{array}$ & $\begin{array}{l}\text { Configuration of } \\
\text { phase } 3\end{array}$ & $M R$ or bursts & Phase $2(\%)$ & $\begin{array}{l}\text { Sum IMA } \\
\text { scores }\end{array}$ & $\begin{array}{l}\text { Duration fed } \\
\text { period }\end{array}$ & Antral MI & fejunal MI & $\begin{array}{l}\text { MR or } \\
\text { bursts }\end{array}$ & $\begin{array}{l}\text { Sum PMA } \\
\text { scores }\end{array}$ \\
\hline 1 & 0 & 0 & 0 & 1 & 1 & 0 & 0 & 0 & 1 (Bursts) & 1 \\
\hline 2 & 0 & 0 & 1 (MR) & 0 & 1 & 0 & 1 & 1 & 1 (MR) & 3 \\
\hline 3 & 0 & 0 & 1 (MR) & 1 & 2 & 0 & 0 & 1 & 1 (MR) & 2 \\
\hline 4 & 0 & 1 & 1 (Bursts) & 1 & 3 & 0 & 0 & 0 & 1 (Bursts) & 1 \\
\hline 5 & 0 & 0 & 0 & 0 & 0 & 1 & 0 & 0 & 0 & 1 \\
\hline 6 & 0 & 0 & 0 & 0 & 0 & 0 & 0 & 0 & 0 & 0 \\
\hline 7 & 0 & 1 & 0 & 0 & 1 & 1 & 0 & 0 & 0 & 1 \\
\hline 8 & 0 & 1 & 0 & 0 & 1 & 0 & 0 & 0 & 0 & 0 \\
\hline 9 & 0 & 0 & 1 (Bursts) & 1 & 2 & 0 & 0 & 0 & 0 & 0 \\
\hline 10 & 0 & 0 & 0 & 0 & 0 & 0 & 1 & 1 & 1 (MR) & 3 \\
\hline 11 & 0 & 0 & 0 & 0 & 0 & 0 & 1 & 1 & 0 & 2 \\
\hline 12 & 0 & 1 & 1 (Bursts) & 0 & 2 & 1 & 1 & 0 & 0 & 2 \\
\hline 13 & 0 & 0 & $1(\mathrm{MR})$ & 0 & 1 & 0 & 0 & 0 & 1 (MR) & 1 \\
\hline 14 & 0 & 0 & 0 & 1 & 1 & 0 & 1 & 0 & 0 & 1 \\
\hline
\end{tabular}

MR, minute rhythm 


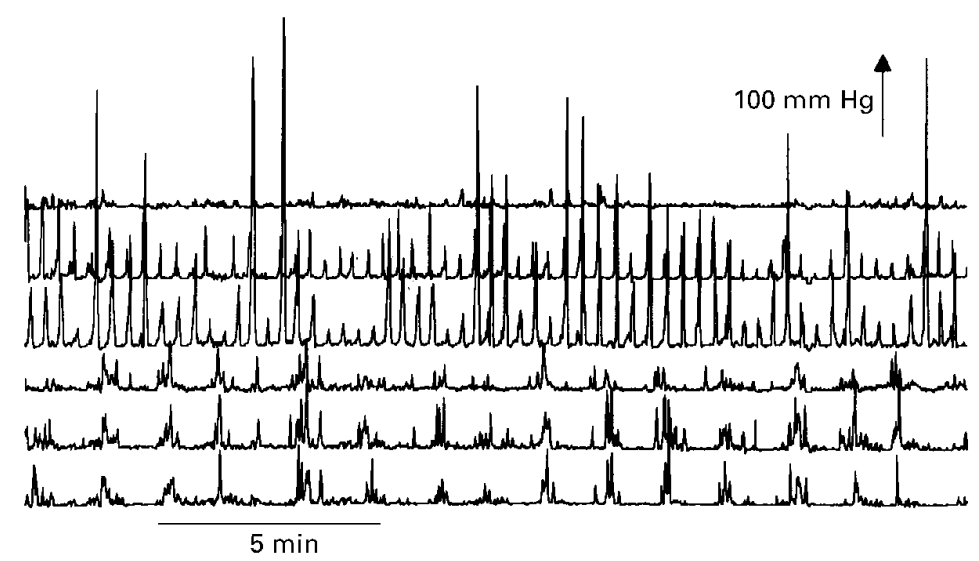

Figure 4 Postprandial manometric recording of the antrum (upper three channels) and of the jejunum (lower three channels) in a patient with motility-like dyspepsia. In the jeujnum a typical minute rhythm pattern can be observed; in the antrum there is intense contractile activity.

and a burst preceding the onset of epigastric pain by three minutes during phase 2 in another patient. Two patients reported epigastric pain or fullness during normal jejunal phase 3, and one patient reported epigastric cramps during an episode of repeated PCCs.

\section{DYSMOTILITY SCORES}

Table 3 summarises scores for dysmotility for the individual patients. The sum of the individual scores was slightly higher for the postprandial than for the inderdigestive period (18 versus 15 points). A total of $71 \%$ of patients scored at least one point for the interdigestive period and $78 \%$ scored at least one point for the postprandial period. Only one patient had no points for both scores. During the postprandial period antral hypomotility or hypermotility and the presence of minute rhythm were the most frequent motor abnormalities observed with a prevalence of $29 \%$ for each. During the interdigestive period the most frequent sign of dysmotility was a high contribution of phase 2 to the MMC cycle (more than the mean (2 SD) of healthy volunteers) in $36 \%$ of patients followed by an abnormal configuration of phase 3 in $29 \%$ of patients. Minute rhythm or bursts were less prevalent than during the postprandial period (each in $20 \%$ of patients). Table 4 summarises symp-

Table 4 Individual data of 14 patients with severe motility-like dyspepsia

\begin{tabular}{llllll}
\hline Patient & $\begin{array}{l}\text { Weight } \\
\text { loss }(\mathrm{kg})\end{array}$ & $\begin{array}{l}\text { Symptom } \\
\text { score }\end{array}$ & $T^{1 / 2}(\mathrm{~min})$ & $\begin{array}{l}\text { Sum IMA } \\
\text { scores }\end{array}$ & $\begin{array}{l}\text { Sum PMA } \\
\text { scores }\end{array}$ \\
\hline 1 & 16 & 7 & $130^{\star}$ & 1 & 1 \\
2 & 16 & 7 & $117^{\star}$ & 1 & 3 \\
3 & 10 & 5 & $127^{\star}$ & 2 & 2 \\
4 & 10 & 5 & 90 & 3 & 1 \\
5 & 10 & 4 & $158^{\star}$ & 0 & 1 \\
6 & 8 & 5 & $137^{\star}$ & 0 & 0 \\
7 & 0 & 4 & $121^{\star}$ & 1 & 1 \\
8 & 0 & 3 & $276^{\star}$ & 1 & 0 \\
9 & 0 & 2 & $71^{\star}$ & 2 & 0 \\
10 & 0 & 2 & 98 & 0 & 3 \\
11 & 0 & 3 & $70^{\star}$ & 0 & 2 \\
12 & 0 & 3 & $110^{\star}$ & 2 & 1 \\
13 & 0 & 2 & $130^{\star}$ & 1 & 1 \\
14 & 0 & 3 & $184^{\star}$ & 1 & \\
\hline
\end{tabular}

$\mathrm{T}^{1 / 2}$, gastric half emptying time of solid food; IMA, score for interdigestive motor activity; PMA, score for postprandial motor activity.

*Abnormal values for gastric half emptying times. tom scores, amount of weight loss, gastric half emptying times, and IMA and PMA scores for individual patients. Correlation analysis between these variables showed a positive correlation only between symptom scores and weight loss $(r=0.93,95 \%$ confidence interval 0.78 to 0.98$)$.

\section{Discussion}

Motor disturbance is one of several factors that have been implicated as a possible aetiopathogenic mechanism in functional dyspepsia. In spite of numerous studies with stationary antroduodenal or duodenojejunal manometry ${ }^{1-5}$ and two studies with either ambulatory antroduodenal or duodenojejunal manometry, ${ }^{67}$ it has not been possible to identify a typical manometric pattern of fasting or postprandial motor activity that distinguishes functional dyspepsia from health. However, a direct comparison between stationary and ambulatory gastroduodenal manometry in patients with functional dyspepsia concluded that the ambulatory method is superior to the stationary method for evaluating motor function in patients with this disorder. ${ }^{6}$ Furthermore, computer aided analysis of these prolonged recordings has been reported to provide more accurate analysis of the manometric signals. ${ }^{12}$ In the present study we combined prolonged, ambulatory antrojejunal manometry with computer aided, detailed manometric analysis in a group of patients with severe motility-like dyspepsia in the hope of obtaining new insights that would reveal quantitative or qualitative differences in motility patterns specific to these patients.

Our findings are in agreement with previous studies in many respects. Malagelada and Stanghellini reported a prevalence of $72 \%$ of manometric abnormalities in a cohort of 104 patients with functional upper gut symptoms studied with stationary antroduodenojejunal manometry. ${ }^{1}$ In our group of patients we also found a high prevalence of antral and jejunal dysmotility both during the interdigestive period ( $71 \%$ of patients) and in the postprandial period $(78 \%)$. During the interdigestive period there were three quantitative parameters that were significantly different between the patient group and the healthy controls: in dyspeptics the incidence of antral or jejunal phase $3 \mathrm{~s}$ was reduced and the relative contribution of phase 2 to the MMC cycle was increased. These observations confirm previous findings, ${ }^{67}$ and the reference values obtained in the healthy volunteers are in accordance with other studies using ambulatory manometry. ${ }^{24}$ Phase 3 has been interpreted as having a housekeeper function by causing rapid aboral and effective propagation of intraluminal contents. ${ }^{19}$ It is possible that the reduced incidence of antral and jejunal phase 3 in dyspeptics contributes to stasis of intraluminal contents, thereby increasing symptom production. The potential clinical relevance of a relatively longer contribution of phase 2 to the MMC cycle at night is not readily apparent, but might be indicative of continued central nervous system arousal which is associated 
with phase 2 motor activity during waking hours. The most frequent qualitative abnormalities observed during the interdigestive period were an abnormal configuration of phase 3 (29\% of patients) and the presence of minute rhythm or repeated bursts of sustained phasic pressure activity (each in $21 \%$ of cases). None of the quantitative or qualitative parameters found to be abnormal during the interdigestive period are specific for dyspepsia and have been described previously both in patients with functional dyspepsia ${ }^{1-7}$ as well as in patients with other disorders. ${ }^{25-29}$

During the postprandial period group comparisons of quantitative parameters, including cumulative antral or jejunal motility indices, the duration of the fed pattern or the number of propagated clustered contractions per hour, did not reveal significant differences between the patients and the healthy volunteers. When comparing values for individual patients with the mean ( $2 \mathrm{SD}$ ) of healthy volunteers, $21 \%$ had postprandial antral hypomotility and 29\% had jejunal postprandial hypermotility or hypomotility. Antral hypomotiltiy has been consistently described in previous studies with stationary manometry and may be expected in $25-40 \%$ of patients. ${ }^{4}$ Patients with functional dyspepsia studied with ambulatory, antroduodenal manometry were found to have mean antral motility indices which were significantly lower after breakfast but not after dinner, while mean small intestinal motility indices were observed to be higher after dinner yet not after breakfast. ${ }^{6}$ In our study, the most frequent qualitative abnormalities observed during the postprandial period were the presence of minute rhythm in $29 \%$ of patients and repeated bursts of sustained phasic pressure activity in $14 \%$ of cases. Both of these motility patterns have been observed previously ${ }^{137}$ and have been described in conditions as diverse as irritable bowel syndrome, ${ }^{9}$ diabetes mellitus, ${ }^{30}$ bacterial overgrowth, ${ }^{27}$ and partial intestinal obstruction..$^{21} 31$

In this study only $4 / 19$ symptom episodes (21\%) were found to be temporally related to an abnormal motor pattern. In contrast, Jebbink et al found motility abnormalities such as burst activity or abnormally propagated phase 3 associated with symptom episodes in $52 \%$ of patients with functional dyspepsia. ${ }^{7}$ The reason for this discrepancy is unclear, but is similar to ambulatory, manometric studies of patients with irritable bowel syndrome; some investigators have reported an association of clustered contractions with abdominal pain in $68 \%$ of patients ${ }^{9}$ while others have reported it in only $7 \% .^{25}$

We also established a motility score for both the interdigestive and the postprandial period to correlate dysmotility with clinical symptoms or gastric half emptying times. The underlying rationale for this step was the assumption that if we could find a positive correlation between severe symptom scores, significant weight loss, abnormally delayed gastric half emptying times, and a high dysmotility score, we could narrow down the indication for the procedure and increase the chances of obtaining clinically useful information in selected patients. However, despite the fact that $71 \%$ of our patients had clearly delayed gastric emptying and $43 \%$ were losing weight, a positive correlation was found only for the symptom score and weight loss. These results suggest that in severe motility-like dyspepsia clinical symptoms or gastric half emptying times are poor predictors of gastrointestinal dysmotility.

Detailed assessment of antrojejunal motor activity, even with the aid of the most recent technological developments in manometric equipment and software algorithms, and selection of a group of patients with severe symptoms, did not allow identification of a specific motor pattern which can uniformly discriminate patients with dyspepsia from those with other diseases or even healthy individuals. This result highlights the unresolved question of the clinical usefulness of this procedure for this indication. While, in our opinion, in selected individual patients this type of manometric study will contribute to clinical decision making and have an impact on treatment, it appears that little clinically valuable information can be gained when performing manometric studies as a routine procedure for patients in whom the diagnosis of functional dyspepsia has already been made. Many gastroenterologists believe that motility disturbances are causally related to dyspepsia. Indeed, there is a high prevalence of dysmotility in dyspeptic patients. However, the absence of a correlation between symptoms and dysmotility and the presence of abnormal motor patterns in only $21 \%$ of symptom episodes argues against a causal relationship between symptoms and dysmotility, and suggests that they are a manifestation of a common underlying aetiopathogenic mechanism.

In conclusion, this study confirms that in patients with severe motility-like dyspepsia, abnormal motility is not only confined to the stomach, but is also highly prevalent in the proximal small intestine. The features of dysmotility found in these patients are more prominent in the postprandial than in the interdigestive period yet are not specific to dyspesia. No single or combined parameter characterising fasted or digestive motor activity in the antrum or jejunum is correlated with the severity of symptoms or the gastric half emptying times.

Part of this work was presented as a poster at the annual meeting of the American Gastroenterological Association in New Orleans in May 1994.

1 Malagelada JR, Stanghellini V. Manometric evaluation of functional upper gut symptoms. Gastroenterology 1985;88:1223-31.

2 Kerlin P. Postprandial antral hypomotility in patients with idiopathic nausea and vomiting. Gut 1989;30:54-9.

3 Stanghellini V, Ghidini C, Maccarini MR, Paparo GF, Corinaldesi R, Barbara L. Fasting and postprandial gastrointestinal motility in ulcer and non-ulcer dyspepsia. Gut 1992;33:184-90.

4 Mearin F, Malagelada J-R. Upper gut motility and perception in functional dyspepsia. Eur $f$ Gastroenterol Hepatol 1992;4:615-21.

5 Bassotti G, Pelli MA, Morelli A. Duodenojejunal motor activity in patients with chronic dyspeptic symptoms. F Clin Gastroenterol 1990;12:17-21.

6 Jebbink HJA, van Berge-Henegouwen GP, Akkermans LMA, Smout AJPM. Antroduodenal manometry: 24-hour LMA, Smout AJPM. Antroduodenal manometry: 24-hour
ambulatory monitoring versus short-term stationary man- 
ometry in patients with functional dyspepsia. Eur f Gastroenterol Hepatol 1995;7:109-16.

7 Jebbink HJA, van Berge-Henegouwen GP, Akkermans LMA, Smout AJPM. Small intestinal motor abnormalities in patients with functional dyspepsia demonstrated by ambulatory manometry. Gut 1996;38:694-700.

8 Lindbergh G, Iwarzon M, Stal P, Seensalu R. Digital ambulatory monitoring of small bowel motility. Scand $f$ Gastroenterol 1990;25:216-24.

9 Kellow JE, Gill RC, Wingate DL. Prolonged ambulatory recordings of small bowel motility demonstrate abnormalities in the irritable bowel syndrome. Gastroenterology 1990 98:1208-18.

10 Huseby E, Skar V, Aalen OO, Osnes M. Digital ambulatory manometry of the small intestine in healthy adults. Estimation of variation within and between individuals and statistical management of incomplete MMC periods. Dig Dis $S c i$ 1990;9:1057-65.

11 Waldron B, Smith D, Storey BE, White G, Campbell FC. Development and validation of microcomputer analysis of Development and validation of microcomputer analysis of 1992;4:301-15.

12 Benson MJ, Castillo FD, Wingate DL, Demetrakopulos J, Spyrou NM. The computer as referee in the analysis of human small bowel motility. Am f Physiol 1993;264:G64554.

13 Widmer R, Schmidt T, Pfeiffer A, Kaess H. Computerized analysis of small-bowel manometry. Scand $\mathcal{F}$ Gastroenterol 1994;29:1076-82.

14 Andrioli A, Wilmer A, Coremans G, Vandewalle J, Janssens J. Computer-supported analysis of continuous ambulatory manometric recordings in the human small bowel. Med Bio Eng Comput 1996;34:336-43.

15 Talley NJ, Colin-Jones D, Koch KL, Koch M, Nyrén O, Stanghellini V. Functional dyspesia: a classification with guidelines for diagnosis and management. Gastroenterology International 1991;4:145-60.

16 Ghoos YF, Maes BD, Geypens BJ, et al. Measurement of gastric emptying rate of solids by means of a carbon-labeled tric emptying rate of solids by means of a carbon-labeled

17 Sarna SK, Soergel KH, Harig JM, et al. Spatial and temporal patterns of human jejunal contractions. Am $\mathcal{f}$ Physio ral patterns of hum

18 Miedema BW, Kelly K, Camilleri M, et al. Human gastric and jejunal transit and motility after Roux gastrojejunostomy. Gastroenterology 1992;103:1133-43.
19 Vantrappen G, Janssens J, Hellemans J, Ghoos Y. The interdigestive motor complex of normal subjects and patients with bacterial overgrowth of the small intestine. $\mathcal{F}$ Clin Invest 1977;59:1158-66.

20 Mearin F, Malagelada JR. Gastrointestinal manometry: a practical tool or a research technique? $\mathcal{f}$ Clin Gastroenterol 1993;16:281-91.

21 Summers RW, Anuras S, Green J. Jejunal manometry in health, partial obstruction, and pseudoobstruction. Gastroenterology 1983;85:1290-300.

22 Kellow JE, Phillips SF. Altered small bowel motility in irritable bowel syndrome is correlated with symptoms. Gastroenterology 1987;92:1885-93.

23 Husebye E, Engedal K. The patterns of motility are maintained in the human small intestine throughout the process of aging. Scand F Gastroenterol 1992;27:397-404.

24 Schmidt T, Widmer R, Pfeiffer A, Kaess H. Effect of the quaternary ammonium compound trospium chloride on 24 hour jejunal motility in healthy subjects. Gut 1994;35: $27-33$.

25 Gorard D, Libby, Farthing M. Ambulatory small intestinal motiltiy in "diarrhoea" predominant irritable bowel syndrome. Gut 1994;35:203-10.

26 Husebye E, Skar V, Torgeir H, Iversen T, Melby K, Engedal $\mathrm{K}$. Abnormal intestinal motor patterns explain enteric colonization with gram-negative bacilli in late radiation enteropathy. Gastroenterology 1995;109:1078-89.

27 Quigley EMM, Donovan JP, Lane MJ, Gallagher TF. Antroduodenal manometry. Usefulness and limitations as an outpatient study. Dig Dis Sci 1992;37:20-8.

28 Kellow JE, Eckersley GM, Jones M. Enteric and central contributions to intestinal dysmotility in irritable bowel syndrome. Dig Dis Sci 1992;37:168-74.

29 Greydanus MP, Camilleri M. Abnormal postcibal antral and small bowel motility due to neuropathy or myopathy in systemic sclerosis. Gastroenterology 1989;96:110-5.

30 Camilleri M, Malagelada JR. Abnormal intestinal motility in diabetics with gastroparesis. Eur F Clin Invest 1984;14:4207.

31 Stanghellini V, Camilleri M, Malagelada JR. Chronic idiopathic intestinal pseudo-obstruction: clinical and intestinal manometric findings. Gut 1987;28:5-12. 